\title{
Common Species Maintain a Large Root Radial Extent and a Stable Resource Use Status in Soil-Limited Environments: A Case Study in Subtropical China
}

Xingyu $\mathrm{Ma}^{1,2,3}$, Hongsong Chen ${ }^{1,2}$ and Yunpeng $\mathrm{Nie}^{1,2^{*}}$

${ }^{1}$ Key Laboratory of Agro-ecological Processes in Subtropical Region, Institute of Subtropical Agriculture, Chinese Academy of Sciences, Changsha, China, ${ }^{2}$ Huanjiang Observation and Research Station for Karst Ecosystems, Chinese Academy of Sciences, Huanjiang, China, ${ }^{3}$ University of Chinese Academy of Sciences, Beijing, China

OPEN ACCESS

Edited by:

Benye Xi,

Beijing Forestry University, China

Reviewed by:

Wenhua Xiang,

Central South University Forestry and Technology, China

Jiacun Gu,

Northeast Forestry University, China

*Correspondence: Yunpeng Nie nyp@isa.ac.cn

Specialty section: This article was submitted to

Plant Abiotic Stress,

a section of the journal

Frontiers in Plant Science

Received: 02 April 2020

Accepted: 30 July 2020

Published: 21 August 2020

Citation:

Ma X, Chen $\mathrm{H}$ and Nie Y (2020) Common Species Maintain a Large Root Radial Extent and a Stable Resource Use Status in Soil-Limited

Environments: A Case Study in Subtropical China.

Front. Plant Sci. 11:1260. doi: 10.3389/fpls.2020.01260
Coarse root systems provide a framework for water and nutrient absorption from the soil and play an important role in plant survival in harsh environments. However, the adaptions of plant roots in soil-limited environments with low water storage capacity and nutrient content needs to be better understood. The adaptation strategies of two common plant species (a deciduous tree Platycarya longipes and an evergreen shrub Tirpitzia ovoidea) from two contrasting habitats (a shallow rocky soil and a nearby deep soil) in a karst region of subtropical China were compared and analyzed. Foliar nutrient concentrations, stoichiometry, stable carbon, and oxygen isotopes were used to determine plant nutrient and water use status across these two habitats. Six indexes, including maximum root depth, maximum root radial extent, number of major roots and secondary roots, and tapering rate and curvature, were all investigated to characterize coarse root systems. Results show that both species exhibited similar nutrient and water use status in the two habitats that had contrasting water holding capacity and available nutrient content. On the other hand, although maximum root depths of the individual plants were not deeper than $33 \mathrm{~cm}$, maximum radial extents were much larger when compared to rooting depths. Specifically, the ratio of radial extent to depth in the soillimited habitat was approximately 6 and 1.5 times higher than that in the deep-soil habitat for the tree and shrub, respectively. Additionally, especially for the tree, a larger root radial extent was further accompanied by lower root tapering rate and bending levels. Our results provided evidence that plants growing in soil-limited environments maintain a stable resource use status along with large radially extended coarse root systems in humid karst regions like southwest China.

Keywords: southwest China, common species, shallow rocky soil, rooting characteristics, plant adaptation, karst ecosystems 


\section{INTRODUCTION}

The growth and survival of any plant is dependent on both above- and below- ground resources (Matyssek et al., 2012). When aboveground resources, such as light and heat, are relatively abundant, the availability of belowground water and nutrients is more critical. Compared with the aboveground of plant (i.e., stems, branches, leaves), roots are much less known because of the difficult, labor-intensive and costly work (Maeght et al., 2013). One of the most important aspects of root systems is the rooting depth. It has long been assumed that the rooting depths of natural vegetation maximize evapotranspiration and are optimized to local climates and soil textures (Milly, 1994). Along with these predicted patterns, based on meta-analysis of global data, it was found that, in wet regions, root systems are shallow compared to infiltration depth; while, in dry regions, root systems are normally deeper and approach maximal infiltration depth (Schenk and Jackson, 2002; Schenk, 2008b). The convergence of theory and fact was investigated for root systems that expand freely in unlimited deep soils (Schwinning, 2010); landforms characterized by shallow soils underlain by hard substrates were usually excluded from consideration.

It is known that plant roots in shallow soil environments absorb water by growing through fractured rock into deeper layers (e.g., Phillips, 1963; Zwieniecki and Newton, 1995; Sternberg et al., 1996; Graham et al., 1997; Hubbert et al., 2001; Graham et al., 2010). With the prevalence of Critical Zone science, plant ecophysiologists have focused on deeper subsurface non-soil resources and the role of deep roots in soil limited environments [recently reviewed by Dawson et al. (2020)]. Karst regions are one of the most typical shallow soil profiles and occupy $10-15 \%$ of the total continental area (Ford and Williams, 2013). Most weathered materials that are derived from the soluble carbonated bedrock are removed by water flow, thus resulting in shallow soil coverage (Cao et al., 2005). A series of studies conducted in karst regions provide evidence for the dominance of deep root systems that access groundwater or perched water tables (Jackson et al., 1999; Querejeta et al., 2007; Nie et al., 2011; Estrada-Medina et al., 2013; Gu et al., 2015; Ding et al., 2018). Poot and Lambers (2008), in southwestern Australia, further reported that seedlings of shallow-soil endemics employed specialized root strategies for exploration of deeper resources. Accordingly, deep root penetration is the main strategy employed by plants in soillimited karst environments.

Not all studies support the viewpoint that deep root penetration is a necessary strategy for plants adapted to shallow soil environments. For example, recent studies suggest that roots of adapted species in typical karst terrains were restricted to shallow soil layers (Heilman et al., 2009; Kukowski et al., 2013; Ni et al., 2015; Dammeyer et al., 2016; Du et al., 2019). Nie et al. (2014a) excavated the coarse root systems of two common species in a karst region of southwest China, and showed that common species, from a variety of habitats, exhibited lateral (almost horizontal) rather than vertical root systems. Furthermore, not all habitats provide fractured substrate. So, unlike endemic species adapted to shallow soils underlain by fractured bedrock, common species, adapting to other types of karst habitats, have developed other rooting characteristics. A complex structure of fine roots is generally considered an indicator of resource absorption and utilization (McCormack et al., 2015). However, in soil-limited environments, where fine roots are difficult to sample at an individual level, investigating and understanding the coarse root pattern is of great significance for understanding plant water and nutrient acquisition (Schenk and Jackson, 2002; Schwinning, 2010; Nie et al., 2011; Maeght et al., 2013). Furthermore, in those soil-limited environments that have a low nutrient content per soil volume, coarse root systems play an even greater role by extending the range of resources acquisition.

The extent of a root system is often predicted by the size of aboveground and climatic regimes, especially by the growth form of the plant (Schenk and Jackson, 2002). For example, rooting depth and lateral root spread generally increase as we progress from herb, to shrub to tree (Peek et al., 2005). Additionally, the root to canopy ratio also differs, i.e. trees have a higher root extent to depth ratio than shrubs. The close relationship between the plant growth form and root dimensions may be due to the resource demands of the plant (Schenk and Jackson, 2005). For example, trees tend to have the deepest and widest lateral spread roots to supply water and nutrient to their leaf biomass. Shrubs are next, then forbs and grasses (Han et al., 2005; Westoby and Wright, 2006). Locally, plant-rooting depths may vary substantially from general patterns. More research needs to be done on the variations in rooting characteristics among species of different plant growth forms. It is understood that trees can obtain additional resources and maintain a stable use of resources because their roots penetrate deeply into bedrock fractures. We need to determine if plants with shallow lateral root systems can also use resources in a stable manner.

One way to determine if a plant can meet normal growth needs in soil-limited habitats is to look at water and nutrient utilization of these same plants in unrestricted environments. Leaf nutrient content and stoichiometry are important indicators of plant nutrient utilization (Koerselman and Meuleman, 1996; Güsewell, 2004). Researches have shown that some species growing in harsh environments have a higher capacity to store $\mathrm{N}$ and $\mathrm{P}$ than those in moderate environments (Chapin et al., 1990) or they have higher nutrient resorption (Aerts and Chapin, 1999). In other words, once the root systems of a species growing in a soil-limited environment can no longer extract similar levels of nutrients as in a deep-soil environment, foliar nutrient content and/or stoichiometry will change (Henry et al., 2005). In terms of water utilization, studies have suggested that, even for the same species, water use varies based on the type of water environment. The most common regulation method is water use efficiency (WUE), plants tend to enhance WUE under drought stress (Querejeta et al., 2006). Leaf $\delta^{13} \mathrm{C}$ is a good proxy indicator of leaf-level intrinsic WUE, generally, $\mathrm{C}_{3}$ plants with high leaf $\delta^{13} \mathrm{C}$ are thought to have high WUE (Dawson et al., 2002). Moreover, a dual isotopic measurement combining $\delta^{13} \mathrm{C}$ and $\delta^{18} \mathrm{O}$ (which is independent of variations in net photosynthetic rate) can help 
untangle the separate effects of carbon assimilation and stomatal conductance on leaf $\delta^{13} \mathrm{C}$ and WUE and allows for a more comprehensive reflection of plant WUE (Prieto et al., 2018).

Plants adaptation strategies in soil-limited environments was performed on two common species (a deciduous tree, Platycarya longipes, and an evergreen shrub, Tirpitzia ovoidea) from a shallow rocky soil and a nearby deep soil in a karst region of subtropical China. The main objectives of this study are: (a) to explore whether the common species growing in soil-limited habitats maintain comparable resource use status to the same species growing in nearby deep soils, (b) to reveal the associated characteristics of coarse root systems and the probable differences between habitats, and (c) to investigate whether the environmental effects on two common species are species-specific.

\section{MATERIALS AND METHODS}

\section{Study Site}

The study was conducted in a small catchment with an area of $1.14 \mathrm{~km}^{2}$ in the Huanjiang Observation and Research Station for

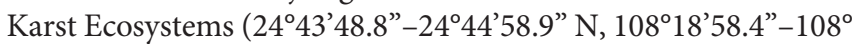
$19^{\prime} 56.9^{\prime \prime}$ E) administrated by the Chinese Academy of Sciences, located in Guangxi Zhuang Autonomous Region, southwest China. The region experiences a typical subtropical monsoon climate, with a mean annual precipitation of $1389 \mathrm{~mm}$ and a mean annual temperature of $19^{\circ} \mathrm{C}$. Rainfall mostly occurs from late April to the end of September, which accounts for $74 \%$ of the total annual rainfall. This catchment is characterized by a flat depression (approximately $0.06 \mathrm{~km}^{2}$ ) surrounded by mountain ranges, except on the northeast side (the mouth of the catchment). Elevation ranges from 272.0 to $647.2 \mathrm{~m}$. Hillslopes are steep $\left(62 \%\right.$ are greater than $\left.25^{\circ}\right)$ and $60 \%$ of the slopes are dominated by shallow soil $(10-30 \mathrm{~cm}$ on average, underlain by weathered or consolidated bedrock) and loose rocky soil (usually a thin layer of coarse gravel underlain by a thick layer of soil and rock fragments) habitats. Rocky outcrops prohibit further expansion of these soil habitats.

The study site was under cultivation before being abandoned at the end of the 1980s. It then experienced approximately 35 years of natural recovery (Chen et al., 2011). Presently, $70 \%$ of the hillslopes are dominated by tussocks and shrubs (Nie et al., 2012), and the vegetation shows three secondary communities: tussock, shrub, and secondary forest from uphill to middle and to foot of the slope; there are also some trees sparsely distribute in the middle of the slope, such as P. longipes and Celtis biondii.

\section{Habitats and Species Selection}

We selected a shallow rocky soil habitat with high rock fragment content (Habitat I) and a nearby deep soil habitat (Habitat II) as comparison. Both of these habitats are located mid-slope and have the same aspect, which excludes the effects of slope position and aspect on plant rooting characteristics. They represent typical habitats of subtropical karst in China. Soil in habitat I is barren and has relatively poor water capacity, while in habitat II, the soil is thicker and has a higher water capacity and resource availability with a more uniformly moderate fertility (Table 2).

In habitat $\mathrm{I}$, the plant community is shrubland dotted with a few trees, the main species are P. longipes, T. ovoidea, C. biondii, and Leptodermis ovata. While in habitat II, the plant community is mainly composed of trees, the main species were P. longpies, T. ovoidea, and Mallotus philippensis. Based on field investigation, we found that a deciduous tree, P. longipes, and an evergreen shrub, T. ovoidea, are common species growing in both selected habitats. They are also found to be widely spread in the karst regions of southwest China. Plots $(20 \mathrm{~m} \times 20 \mathrm{~m})$ were established for each of the two habitat types, with a distance between plots was $800 \mathrm{~m}$ (see Supplementary Figure S1 for details). Three to six mature individuals (indicated by their ability to set seed) per species per habitat were sampled randomly for further investigation. Basal information of the selected plants is shown in Table 1. Specifically, individuals of $P$. longipes in habitat I usually have basal branches, only the DBH of the biggest branch was shown in Table 1 .

\section{Field Sampling and Laboratory Analysis}

In August 2017, mature, sunlit leaves were collected from each sample plant individual of each species in both habitats. There were nine samples (six for $P$. longipes and three for T. ovoidea) in habitat I and seven samples (four for $P$. longipes and three for $T$. ovoidea) in habitat II, respectively, for a total of 16 leaf samples. All samples were oven-dried at $70^{\circ} \mathrm{C}$ to constant weight and ground for further analysis.

Soil samples were also collected in August 2017. Three soil cores (15 cm depth) were taken randomly around each sample root and thoroughly mixed into one composite sample. The composite samples were placed in polyethylene bags and transported to the laboratory. After they were air dried, the soil

TABLE 1 | Major information of the common, dominant species: P. longipes and T. ovoidea, in two distinct habitats in a karst ecosystem of southwest China.

\begin{tabular}{|c|c|c|c|c|c|c|c|}
\hline Species & Family & Habitat & Leaf phenology & Number of basal branches & $\mathrm{DBH}^{*}(\mathrm{~cm})$ & Height (m) & Estimated age (a) \\
\hline \multirow[t]{2}{*}{ P. longipes } & Juglandaceae & Habitat I** & Deciduous tree & $2.5 \pm 1.43$ & $6.97 \pm 1.63^{\mathrm{b}}$ & $3.17 \pm 0.45^{\mathrm{b}}$ & $11.33 \pm 0.58$ \\
\hline & & Habitat II & & -- & $11.95 \pm 3.55^{\mathrm{a}}$ & $5.93 \pm 1.11^{\mathrm{a}}$ & $12.67 \pm 2.52$ \\
\hline \multirow[t]{2}{*}{ T. ovoidea } & Linaceae & Habitat I & Evergreen shrub & $4.3 \pm 1.47$ & $2.71 \pm 1.03$ & $1.56 \pm 0.18^{b}$ & - - \\
\hline & & Habitat II & & $2.2 \pm 1.09$ & $3.23 \pm 0.91$ & $2.90 \pm 1.15^{\mathrm{a}}$ & - \\
\hline
\end{tabular}

${ }^{*}$ For tree species, this refers to the diameter at breast height; for shrub species, this refers to the base diameter. Additionally, plants in habitat I usually have 2 or 3 basal branches, of which

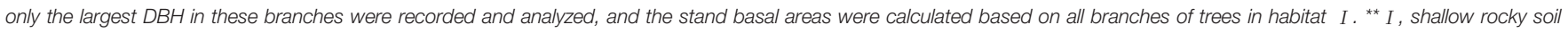
(frequently, <30 cm depth), weakly weathered bedrock layer underlain. II, nearby deep soil (>50 cm depth), deep and homogenous soil. "- -" means no annual ring data. Means in a column of same species followed by different letters are significantly different according to one-way ANOVA and LSD ( $P<0.05)$. Values are mean $\pm S D$. 
samples were ground and passed through a $2 \mathrm{~mm}$ mesh sieve for physicochemical analysis.

Soil organic carbon (SOC) was measured by the potassium dichromate method. Total soil N (TN) was measured by the Kjeldahl determination, and total soil $\mathrm{P}$ (TP) was determined by acid digestion with a $\mathrm{H}_{2} \mathrm{SO}_{4}+\mathrm{HClO}_{4}$ solution. Alkalihydrolyzable $\mathrm{N}(\mathrm{AN})$ was measured by titration with a dilute solution of $\mathrm{H}_{2} \mathrm{SO}_{4}$ after samples had been extracted with a mixture of $\mathrm{FeSO}_{4}$ and $\mathrm{NaOH}$. After samples were extracted with $0.5 \mathrm{M} \mathrm{Na}_{2} \mathrm{CO}_{3}$, available phosphorus (AP) was measured by the molybdenum blue colorimetric method. Concentrations were expressed on the basis of oven-dry soil weight. Gravimetric soil moisture content was determined by drying soil samples in an oven at $105^{\circ} \mathrm{C}$ for at least $72 \mathrm{~h}$. Leaf $\mathrm{N}$ concentration was measured with a flow injection analyzer (FIAstar 5000, FOSS, Sweden). Leaf $\mathrm{P}$ concentration was measured with the molybdate/ascorbic acid method. Leaf $\delta^{13} \mathrm{C}$ and $\delta^{18} \mathrm{O}$ were measured by Isoprime isotope ratio mass spectrometer (IRMS; MAT 253, Thermo Fisher Scientific, Inc., GER), in the Key Laboratory of Agro-ecological Processes in Subtropical Region, Institute of Subtropical Agriculture, Chinese Academy of Sciences.

The soil water capacity for the two habitats were cited from the doctoral thesis completed by Fu (2017), which used the grid $(80 \mathrm{~m} \times 80 \mathrm{~m})$ sampling method in the studied catchment. In his study, a soil core was used to collect soil samples at five points from the surface $(0-15 \mathrm{~cm})$ and around each grid intersection. Parameters such as rock fragment content (RC), soil texture (sand and clay content), and soil organic carbonate (SOC) were measured. It is worth noting that gravel particle sizes that were larger than the diameter of the soil core $(38 \mathrm{~mm})$ were generally ignored during sampling. We selected three sample sites around the shallow rocky soil habitat and the nearby deep soil habitat from Fu's research and then analyzed their mean values of RC, sand and clay content, and SOC to represent the soil physicochemical properties in the two habitats. Rawls model (Rawls et al., 1982) was used for estimating the field capacity and wilting coefficient of soil $(0-15 \mathrm{~cm})$ in the sample habitats to reduce laboratory work, and after that, available water capacity (AWC) was calculated accordingly. Multiple regression formulas of Rawls model are as follows:

$$
\begin{gathered}
\theta_{f}^{*}=0.2576-0.0020 P_{s}+0.0036 P_{c}+0.0299 P_{o c} \\
\theta_{w}=0.0260+0.0050 P_{c}+0.0158 P_{o c}
\end{gathered}
$$

${ }^{*} \theta_{\mathrm{f}}$, soil field water capacity. $\mathrm{P}_{\mathrm{s}}$, soil sand content. $\mathrm{P}_{\mathrm{c}}$, soil clay content. $\mathrm{P}_{\mathrm{oc}}$, soil organic carbon. $\theta_{\mathrm{w}}$, soil wilting coefficient.

\section{Root Investigation}

Root characteristics were investigated by manually excavating intact root systems of the selected plants between August and October 2017. All main roots arising from the base of the target plants were identified first, lateral roots were then exposed by following the exposed main roots. Roots from other plants were easily distinguished as they were not connected to the main root. Roots with diameters of $<0.5 \mathrm{~cm}$ were not measured because they break easily, and it was difficult to determine their origin. Broken roots were reconnected with adhesive tape. We analyzed the fine root biomass in different soil layers at the community level. However, because of the difficulties in distinguishing which plant the roots emanate from using soil cores and minirhizotron, the fine roots at the individual level were not taken into account in this study.

When the whole root system was exposed, maximum rooting vertical depth (VD) and maximum radial extent (RE) were both measured. Other parameters, such as curve length (CL), straight length (SL), root diameter (RD), and the number of main and lateral roots, were also recorded. Information on the root investigation indexes is found in Figure 1. We measured CL, the length from the base of stem to the distal along the main roots. Roots were then marked at regular intervals according to the CL (every $10 \mathrm{~cm}$ for the first $50 \mathrm{~cm}$ and every $50 \mathrm{~cm}$ after that), and RD was measured based on these marks.

Only mature trees were sampled. The height and diameter of breast height $(\mathrm{DBH})$ varied markedly, which made direct interplant comparisons of root structure characteristics impossible. In order to eliminate the impact of the variation in size and compare root structure characteristics, we used two plant sizeindependent parameters, root tapering pattern, and root curvature (Nie et al., 2014a). Tapering rate and curvature could be calculated as:

$$
\text { Tapering rate }=\frac{R D_{n}-R D_{n+1}}{C L_{n+1}-C L_{n}}
$$

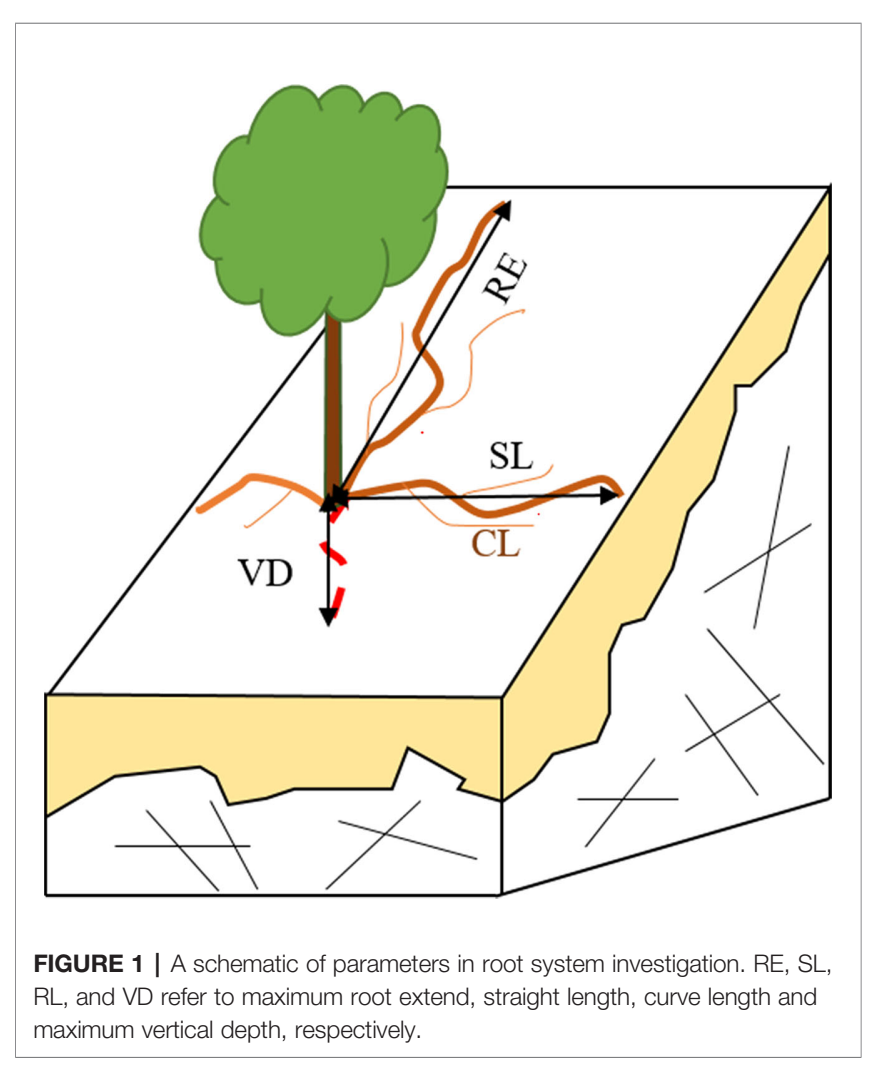




$$
\text { Curvature }=\frac{S L}{C L}
$$

$\mathrm{RD}_{\mathrm{x}}, \mathrm{RD}$ at the mark $\mathrm{X}$ previously made on the root; $\mathrm{CL}_{\mathrm{x}}, \mathrm{CL}$ from plant base to the mark X; CL, curve length; SL, straight length.

Root tapering rate reflects the rate at which the root diameter gradually decreases along RL. The root tapering rate ranges from 0 to 1 . If the value is close to 0 , then the root diameter decreases slowly per length unit. If it is closer to 1 , then root diameter decreases sharply. Root curvature can reflect the degree of root bending. A curvature also ranges from 0 to 1 , a curvature close to 0 indicates a high root bending degree. While, a curvature closer to 1 indicates a relatively linear root pattern.

Both indices were calculated based on the individual plant features, and then, the average of individuals within a species within one habitat was used for statistical analysis and graphing.

\section{Statistical Analysis}

We tested the impact of soil physical-chemical properties on foliar $\mathrm{C}, \mathrm{N}$ and $\mathrm{P}$ concentrations, stoichiometry characteristics and isotopic natural abundance $\left(\delta^{13} \mathrm{C}\right.$ and $\left.\delta^{18} \mathrm{O}\right)$ with a one-way ANOVA followed by the LSD multiple comparison test using at least three replicates per species in each habitat. We calculated the average tapering rate per root segment along CL (separated based on marks on each taproot) and root curvature of each individual. The differences in tapering rate and curvature for each species in different habitats were compared based on the fact that these two parameters showed no significant difference for the same species in the same habitat. Statistical analyses were performed using SPSS 19.0 (SPSS Inc., Chicago, IL, USA) and Origin 9.0 (OriginLab, Hampton, MA, USA).

To evaluate the key factors of plant adaptation strategy in soillimited habitats, we performed a redundancy analysis (RDA) and extracted the scores on the first and second axes of variation of the RDA and the contribution of every trait related to plant adaptive strategy. The statistical significance of RDA results was determined using the Monte Carlo permutation method based on 999 runs with randomized data. Results were considered as statistically significant if $p<0.05$.

\section{RESULTS}

\section{Soil Moisture and Nutrient Conditions in Two Habitats}

As shown in Table 2, significantly shallower soil depth and lower AWC were found in habitat I than in habitat II. Additionally, soil SOC, TP and AP in habitat II were around 3 times higher than in habitat I, and habitat II also exhibited significantly higher soil TN and AN than that in habitat I. Moreover, contrasted to the nearby soil habitat with extremely low gravel content, the gravel content in habitat I reached about 50\% (data not shown). Additionally, ignoring gravel with a diameter greater than $38 \mathrm{~mm}$ led to a greater difference in water and nutrient conditions between the two habitats than was recorded in Table 2.
TABLE 2 | Comparison of soil water holding capacity, moisture conditions and soil nutrient concentrations in two selected habitats in a southwest China karst ecosystem.

\begin{tabular}{|c|c|c|}
\hline Soil condition parameters & Habitat $I^{*}$ & Habitat II \\
\hline Soil depth (SD)(m) & $0.32 \pm 0.04^{b}$ & $0.70 \pm 0.11^{\mathrm{a}}$ \\
\hline Bulk density (BD) $\left(\mathrm{g} \cdot \mathrm{cm}^{-3}\right)$ & $1.46 \pm 0.02^{\mathrm{a}}$ & $0.68 \pm 0.01^{b}$ \\
\hline Rock fragment content (RC) (\%) & $30.83 \pm 6.57^{\mathrm{a}}$ & $10.36 \pm 6.47^{b}$ \\
\hline Filed water capacity ** $\left(\theta_{f}\right)(\%)$ & $27.31 \pm 0.25^{b}$ & $34.32 \pm 0.48^{\mathrm{a}}$ \\
\hline Wilting coefficient ${ }^{* *}\left(\theta_{w}\right)(\%)$ & $14.83 \pm 0.13^{\mathrm{a}}$ & $18.06 \pm 0.28^{a}$ \\
\hline Available water capacity ** (AWC) \% & $12.48 \pm 0.03^{b}$ & $16.26 \pm 0.03^{a}$ \\
\hline $\operatorname{SOC}\left(\mathrm{g} \cdot \mathrm{kg}^{-1}\right)$ & $24.74 \pm 0.09^{b}$ & $78.04 \pm 16.06^{a}$ \\
\hline $\mathrm{TN}\left(\mathrm{g} \cdot \mathrm{kg}^{-1}\right)$ & $0.31 \pm 0.15^{\mathrm{b}}$ & $0.62 \pm 0.12^{a}$ \\
\hline $\mathrm{TP}\left(\mathbf{g} \cdot \mathrm{kg}^{-1}\right)$ & $0.25 \pm 0.08^{b}$ & $0.88 \pm 0.06^{a}$ \\
\hline AN (mg.kg $\left.{ }^{-1}\right)$ & $333.42 \pm 92.76^{b}$ & $766.09 \pm 92.29^{a}$ \\
\hline AP (mg. $\left.\mathrm{kg}^{-1}\right)$ & $3.40 \pm 0.67^{b}$ & $9.78 \pm 0.48^{a}$ \\
\hline
\end{tabular}

* I , shallow rocky soil habitat; II, nearby normal deep soil habitat. * Results of the Rawls model. SOC, soil organic carbon; TP, total soil phosphorus; TN, total soil nitrogen; AN, available nitrogen; AP, available phosphorus; AK, available potassium. Means in a line followed by different letters are significantly different according to one-way ANOVA and $\operatorname{LSD}(p<0.05)$. For $A N$ and $A P, n=4$ in both habitat $I$ and habitat II, for other 8 soil condition parameters, $n=9$ and 7 for habitat $I$ and habitat $I$, respectively. Values are mean $\pm S D$.

\section{Leaf Chemical Characteristics in Two Habitats}

As shown in Table 3, there were no significant differences in foliar $\mathrm{C}, \mathrm{N}, \mathrm{P}$ for the same species in different habitats, or in values of $\mathrm{C} / \mathrm{N}, \mathrm{C} / \mathrm{P}, \mathrm{N} / \mathrm{P}$. The foliar $\mathrm{N}: \mathrm{P}$ ratio was significantly lower in $P$. longipes than in $T$. ovoidea, while both of them were $<14$, reflecting a $\mathrm{N}$ limitation for both of the species in both habitats.

Figure 2 showed that species growing in habitat I exhibited similar foliar $\delta^{13} \mathrm{C}$ values as those growing in habitat II. Specifically, around $-32.44 \pm 0.67 \%$ for $P$. longpies and $-32.94 \pm 0.36 \%$ for $T$. ovoidea. Moreover, leaf $\delta^{13} \mathrm{C}$ was positively correlated with leaf $\delta^{18} \mathrm{O}$ across species in habitat I while not in habitat II (Figure 3).

\section{Root Architectural Traits}

Both of the common species growing in the selected karst habitats exhibited relatively shallow root systems as VD of all the individuals were less than $33 \mathrm{~cm}$ (Table 4). Additionally, the average RE of the two habitats were about 9 and 1.5 times greater than VD for P. longipes and T. ovoidea, respectively.

On the other hand, the lateral root range of both of the species in habitat I were wider than that in habitat II. Especially for $P$. longipes, RE in habitat I was almost three times greater than that in habitat II. Additionally, this extensive radial root extent in habitat I was accompanied by several other parameters. The ratios of root radial extent to depth in habitat I were approximately 6 and 1.5 times greater than that in habitat II for P. longipes and T. ovoidea, respectively. And, the ratios of root radial extent to canopy width in habitat I were 2.5 and 2.9 times higher than that in habitat II for P. longipes and T. ovoidea, respectively. Even though the height of plants growing in habitat II were significantly lower (Table 1), they had significantly larger root radial extension range than those in habitat II. 
TABLE 3 | Foliar nutrient concentrations and stoichiometric characteristics of two habitats in southwest China karst ecosystem.

\begin{tabular}{|c|c|c|c|c|}
\hline \multirow[t]{2}{*}{ Stoichiometry * } & \multicolumn{2}{|c|}{ P. longipes } & \multicolumn{2}{|c|}{ T. ovoidea } \\
\hline & Habitat I & Habitat II & Habitat I & Habitat II \\
\hline Foliar C $\left(\mathrm{g} \cdot \mathrm{kg}^{-1}\right)$ & $46.50 \pm 2.18$ & $48.41 \pm 0.63$ & $46.35 \pm 0.01$ & $46.33 \pm 0.05$ \\
\hline Foliar $\mathrm{N}\left(\mathrm{g} \cdot \mathrm{kg}^{-1}\right)$ & $1.88 \pm 0.09$ & $1.70 \pm 0.17$ & $2.44 \pm 0.19$ & $2.50 \pm 0.18$ \\
\hline Foliar P $\left(\mathrm{g} \cdot \mathrm{kg}^{-1}\right)$ & $0.20 \pm 0.02$ & $0.22 \pm 0.02$ & $0.22 \pm 0.01$ & $0.21 \pm 0.01$ \\
\hline $\mathrm{C} / \mathrm{N}$ & $24.83 \pm 1.76^{a}$ & $28.66 \pm 2.99^{\mathrm{a}}$ & $19.04 \pm 1.45^{\mathrm{b}}$ & $18.55 \pm 1.31^{\mathrm{b}}$ \\
\hline $\mathrm{C} / \mathrm{P}$ & $232.77 \pm 29.92$ & $225.69 \pm 16.88$ & $212.45 \pm 5.54$ & $222.80 \pm 0.55$ \\
\hline $\mathrm{N} / \mathrm{P}$ & $9.36 \pm 0.85^{b}$ & $7.93 \pm 0.96^{b}$ & $11.20 \pm 1.14^{\mathrm{a}}$ & $12.04 \pm 0.88^{a}$ \\
\hline
\end{tabular}

*Means in a line followed by different letters are significantly different according to one-way ANOVA and LSD ( $p<0.05)$. Values are mean \pm SD.

The correlations between plant adaptation traits and environmental factors were shown in Figure 4. Plant adaptation traits, which were correlated to environmental factors, were almost always related to root patterns, which was consistent to the findings shown in Table 4. Specifically, the main environmental factors affecting plant adaptability were RC, bulk density (BD), AN and soil depth (SD). In addition, RE $(P=0.01$, $F=10.3)$ and $\mathrm{RE} / \mathrm{CW}(P=0.11, F=3.2)$ were the strongest quantitative indicators in support of the adaptation of $P$. longipes and T. ovoidea to soil-limited habitats (with high RC and BD, low $\mathrm{AN}$ and SD), respectively.

\section{Root Mechanical Traits}

As shown in Figure 5, in the 0-40 cm section of CL, tapering rates at each root section for $P$. longipes growing in habitat I were significantly lower than that in habitat II. Specifically, in habitat I, all sections of CL $(0-200 \mathrm{~cm})$ were plotted below $0.075 \mathrm{~mm} \mathrm{~cm}^{-1}$ except the $0-10 \mathrm{~cm}$ section, which favored a horizontal extension of roots in the shallow rocky soil habitat. While in habitat II, although the root tapering rates in the section of 50-200 cm were similar to that in habitat I, they were higher within the section of

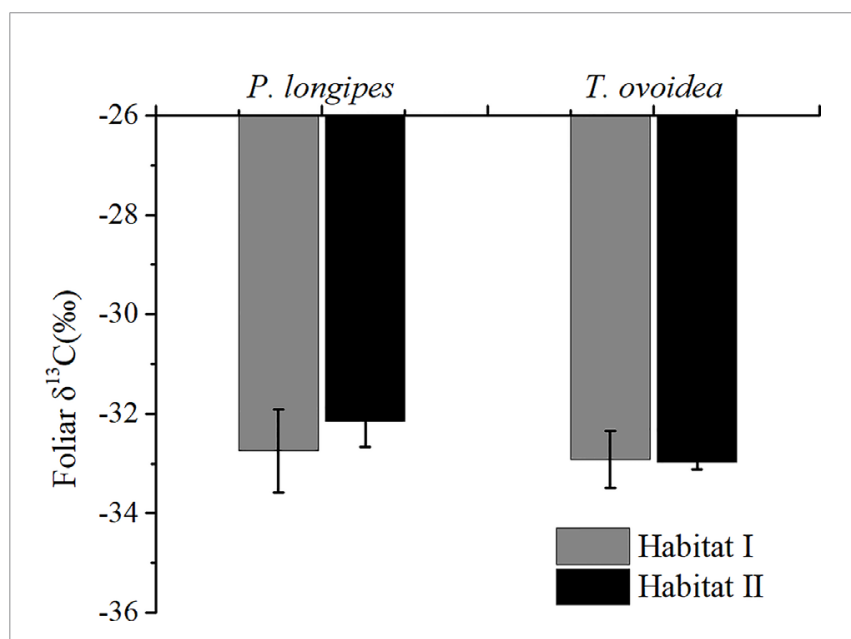

FIGURE 2 | Comparison of mean foliar $\delta^{13} \mathrm{C}$ values for $P$. longipes and $T$. ovoidea growing in the two selected habitats. "Habitat I" indicates values obtained in shallow rocky soil habitat, whereas "Habitat II" refers to values obtained in the nearby deep soil habitat. Error bars represent \pm 1 SD ( $n=9$ and 7 for habitat I and habitat II, respectively). There is no significant difference between species or habitats $(p<0.05)$.
$0-40 \mathrm{~cm}$ (the largest rate was 0.351 at $20 \mathrm{~cm}$, and the average rates were ranging from 0.048 to 0.213 ), which matched their relatively small lateral extension range.

Contrary to the large variation for $P$. longipes growing in different habitats, root tapering patterns of $T$. ovoidea exhibited flat patterns. More specifically, roots of $T$. ovoidea growing in both habitats tapered slightly and barely fluctuated, all sections within the total CL of $0-100 \mathrm{~cm}$ were plotted below the line at $0.075 \mathrm{~mm} \mathrm{~cm}^{-1}$.

As shown in Figure 6, the root curvature of $P$. longipes growing in habitat I $(0.87 \pm 0.03)$ was significantly greater than that in habitat II $(0.75 \pm 0.01)$, which reflected a slighter root bending degree of $P$. longipes in habitat I than that in habitat II.

Contrary to the obvious differences for $P$. longipes, root curvatures of T. ovoidea growing in the two habitats exhibited similar patterns and both of them were higher than 0.8 , indicated that the root extension process of T. ovoidea in both habitats exhibited an approximately linear form.

\section{DISCUSSION}

In the current study, two common species (the tree $P$. longipes and the shrub $T$. ovoidea) growing in a typical rocky habitat and a nearby deep soil habitat were studied to investigate plant adaptations to environmental stress. We found that there was no significant difference in time-integrated WUE (Figure 2) or nutrient status on the leaf level (Table 3) in common species growing in the two contrasting habitats. Our results were contrary to some other studies which found notable differences in water use efficiency (Prieto et al., 2018; Querejeta et al., 2018), nutrient resorption (Brant and Chen, 2015) and stoichiometry (Elser et al., 2000) under different environmental conditions. Which leads one to believe that the undifferentiated characteristics of water and nutrient utilization were related to the plant root adaptations.

Both common species were characterized by shallow root systems in both habitats. Additionally, the maximum root depth of both $P$. longipes and T. ovoidea in both habitats was less than $33 \mathrm{~cm}$ (Table 4). Studies have suggested that the both species are widely found in peaks and the upper hillslopes of karst in southwest China (Yu, 2003; Rong et al., 2012; Du et al., 2017; Ding et al., 2018), with extremely high bare rock (Cao et al., 2014). Based on these results, one would speculate that the survival of these two species in a rocky habitat would benefit from deep roots 

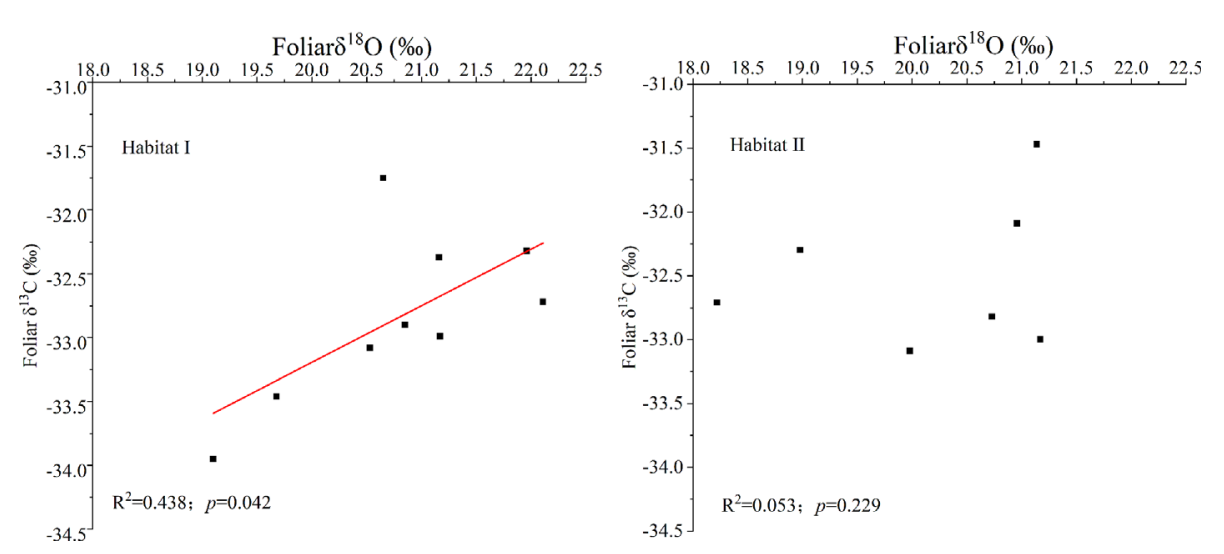

FIGURE 3 | Linear regression of the foliar $\delta^{13} \mathrm{C}$ and $\delta^{18} \mathrm{O}$ values for all of the studied plants (all dots) in habitat I and habitat II. "Habitat I" refers to values obtained in shallow rocky soil habitat, and "Habitat II" refers to values obtained in the nearby deep soil habitat.

TABLE 4 | Coarse root parameters for two common species in two selected habitats in southwest China.

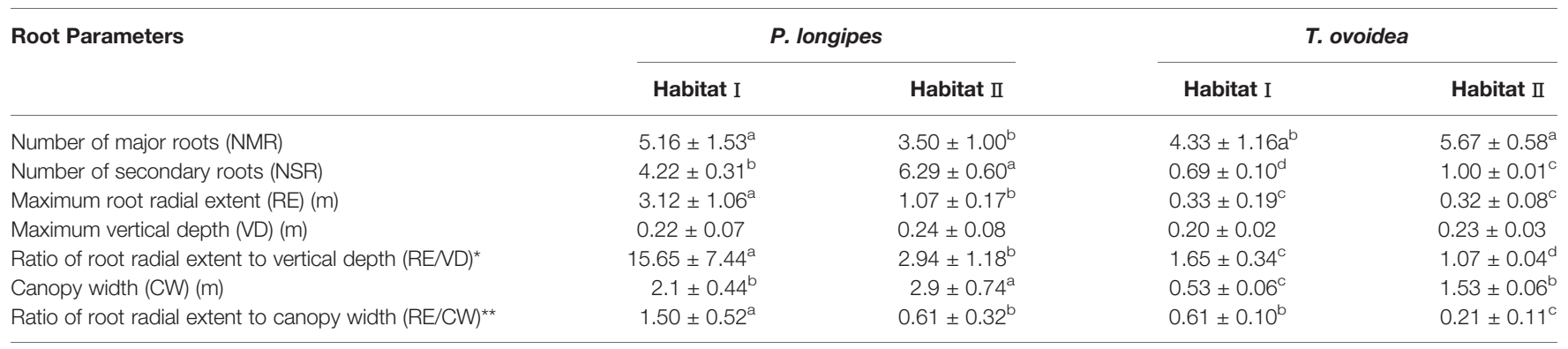

${ }^{*}$ Results of maximum root radial extent versus maximum vertical depth; ** results of maximum root radial extent versus canopy. Means in a line followed by different letters are significantly different according to one-way ANOVA and LSD $(p<0.05)$. Values are mean $\pm S D$.

A

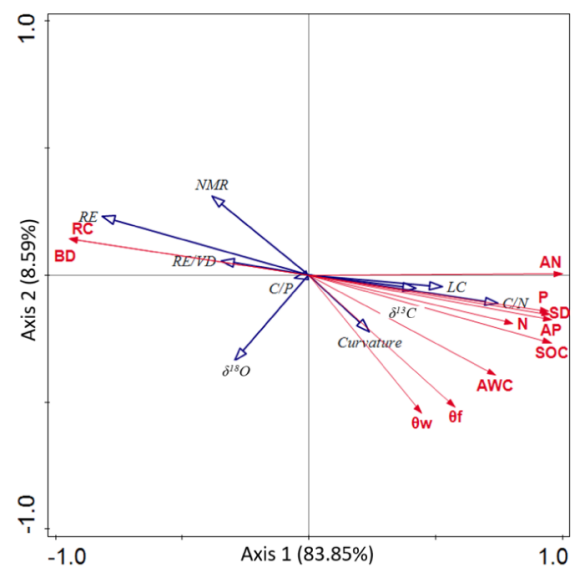

B

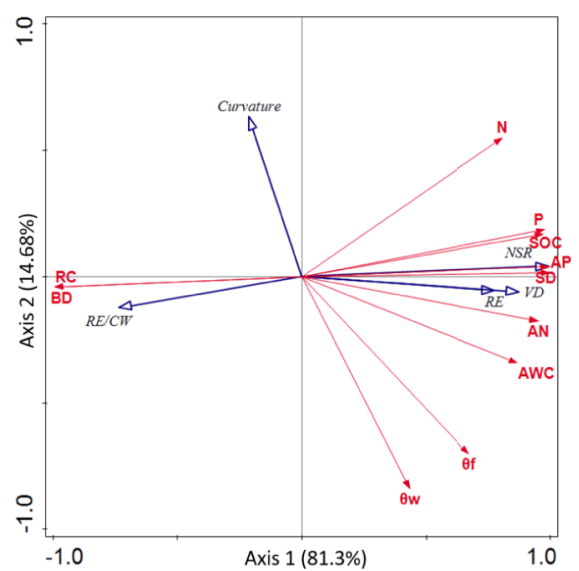

FIGURE 4 | Redundancy analysis (RDA) of leaf nutrient status, water use efficiency, and root structure parameters for adaptation strategy of $P$. longipes (A) and T. ovoidea (B) in two contrasting habitats. Depicted are the soil environmental variables (red arrows) and plant adaptation trait variables (blue arrows). Abbreviations for environmental variables are given in, and abbreviations for leaf nutrient status and root parameters are shown in and.

which penetrate into cracks (Yu, 2003), which is contrary to our findings. Other studies reported that plants prefer deep root penetration to compensate for the shallow soil limitation
(Jackson et al., 1999; Querejeta et al., 2007; Schwinning, 2013; $\mathrm{Gu}$ et al., 2015). While, other researchers agree with our findings, in karst regions, fine and coarse plant roots were distributed in the 

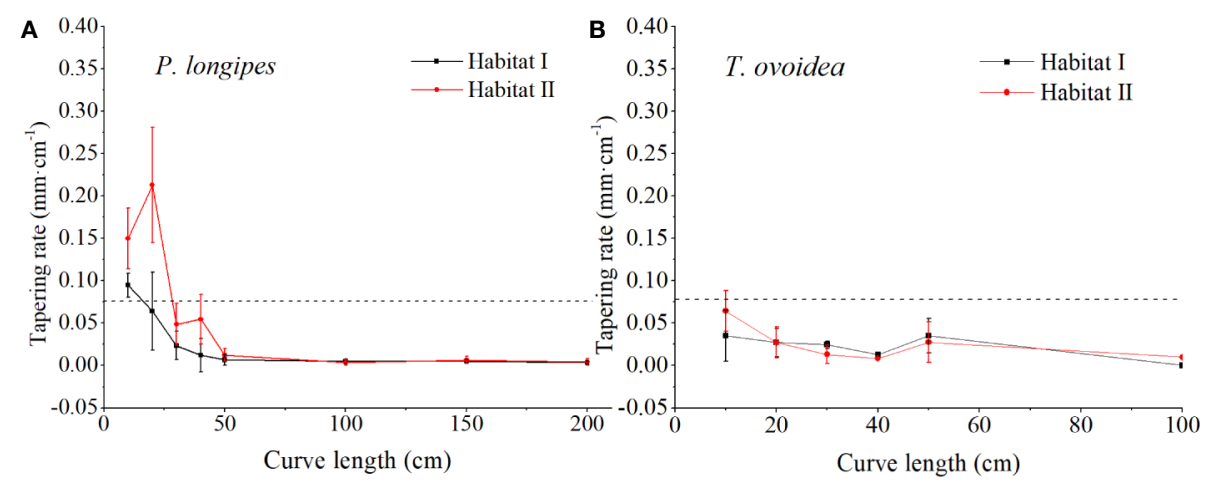

FIGURE 5 | Continuous fluctuation of root tapering rate with increasing root curve length for $P$. longipes (A) and T. ovoidea (B) growing in the two selected habitats. Error bars represent $\pm 1 \mathrm{SD}$. Dotted lines parallel to the axes of the curve length separate root tapering rates greater than or less than $0.075 \mathrm{~mm}^{-1}$.

shallow soil layer (Heilman et al., 2009; Ni et al., 2015; Nie et al., 2017; Du et al., 2019) where the soil is characterized by higher nutrient content, warmer temperature, and roots require less carbon (Steele et al., 1997). These conflicting viewpoints are due to habitat differences and root plasticity of the plant species (Mulia et al., 2010; Isaac et al., 2014). Generally, endemic species in shallow-soil habitat resort to specialized root strategies associated with increasing root biomass close to the bedrock surface to increase their penetration into deeper layers (Poot and Lambers, 2008; Schwinning, 2013). Compared with endemic species, widespread species, like the common species in our study, normally have higher adaptive plasticity (Bastida et al., 2013; Hand et al., 2017), thus, they exhibit varied root characteristics in different habitats (Li et al., 2017).

Compared with the undifferentiated adaptation characteristics of rooting depth, the range of root laterally extent exhibited significantly different traits for each species in the two habitats (Table 4 and Figure 5). Specifically, both species that were growing in soil-limited habitat, have a longer radially extending root than in the nearby deep soil habitat. In the unfavorable conditions for deep rooting, plants need to explore other root characteristics to obtain sufficient soil resources for growth (Semchenko et al., 2018), especially, in a habitat with low water and nutrient contents per soil volume. For example, the shallow rocky soil habitat in our study is characterized by thin soil overlying weakly weathered and shallow bedrock. Previous researches confirmed that when the underlying surface is unfavorable for root penetration, roots are concentrated in the topsoil (Schenk, 2008a; Schenk, 2008b) and favor horizontal extensions (Stone and Kalisz, 1991; Martre et al., 2002). In addition, because of the extremely low water storage capacity per soil volume in the shallow rocky soil habitat, most of the water is lost through subsurface flow occurring in the soilepikarst interface (Fu et al., 2016; Wang et al., 2019). Even in heavy rainfall events, only small amount of rainfall is stored. Therefore, it is the rainfall frequency, which determines the availability of water to plants in these soil-limited habitats, rather than the rainfall amount. Moreover, given that there are more frequent light rainfall events in this region (Yang et al.,
2012), coupled with canopy interception, only shallow soil moisture is replenished. As a consequence, plants obtain a larger range of shallow soil water through the laterally extending root system, not only as an adaptation to the geotechnical environment but also to the rainfall characteristics of the region. Additionally, at least from the aspects of low energy consumption for construction, maintenance, and resource uptake, shallow root systems have an advantage over deep roots (Schenk, 2008b). Furthermore, various studies indicated that wide lateral roots are more efficient for anchoring plants (Ennos, 1993; Schenk and Jackson, 2002).

In addition to the maximum radial root extension, other coarse root parameters, such as the ratio of root extent to canopy width, and root tapering rate and curvature, further facilitate the expansion of horizontal root range in the soil-

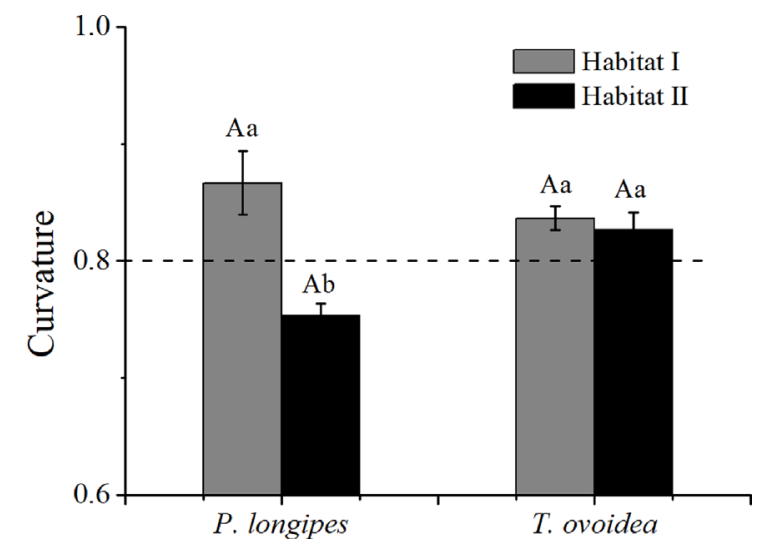

FIGURE 6 | Mean root curvature of $P$. longipes and T. ovoidea from the two habitats. Error bars represent $\pm 1 \mathrm{SD}$ ( $\mathrm{n}=9$ and 7 for habitat I and habitat II, respectively). Dotted lines parallel to the axes of the species separate curvatures that are greater than or less than 0.8. Lowercase letters in the same species stand for significant differences between different habitats $p<$ 0.05). Capital "A" and lowercase "a" denote statistical significance in two habitats and two species, respectively. 
limited habitat. Specifically, both P. longipes and T. ovoidea had a significantly greater ratio of root extent to canopy width in the shallow rocky soil habitat than that in the deep soil habitat (Table 4). According to optimal partitioning theory, plants allocate more biomass to belowground organs when they are experiencing water and nutrient deficit (Reynolds and Thornley, 1982; Lezberg et al., 1999). Just as the root hydrotropism strategy results from water deficit (Baluška et al., 2009), in our study, the high root extent to canopy width ratio also plays an important role for plant survival in water scarcity environments (Poorter et al., 2012; Ledo et al., 2018). Moreover, the gradually tapering and slightly curving roots of the two species in the shallow rocky soil habitat increase the possibility of encountering water and nutrients (Nie et al., 2014a; O'Donnell et al., 2015). Benefiting from the lateral extension, roots can explore a wider resource area and increase the chances of achieving a similar water and nutrient use status as found in a deep soil habitat. Overall, the results of RDA suggested that both species adapted to the environment by root pattern modifications. Specifically, $P$. longipes and $T$. ovoidea growing in habitats characterized by shallow soil with high rock content and bulk density favor large root extension and high ratio of root extent to canopy width, respectively (Figure 4 and Table 4). Both species growing in the deep soil habitat also exhibit shallow root systems like those growing in the soil-limited habitat, but no large coarse lateral extension roots. They have a greater number of secondary roots and a higher bending degree, which was conducive to using soil resources found around the basal stem efficiently (Pregitzer et al., 2002; Shan et al., 2007; Nie et al., 2014a; Kong et al., 2016; Valverde-Barrantes et al., 2017).

Although, the distinction in root structures of both species in the two contrasting habitats were consistent, the difference in $P$. longipes was more obvious than in T. ovoidea (Table 4). This discrepancy relates to the plant growth form (tree and shrub), the leaf phenology (deciduous and evergreen), and/or the aboveground plant size (Peek et al., 2005). Generally, plants with bigger aboveground mass require more resources for sustaining growth and respiration than those with smaller aboveground mass (Han et al., 2005). In order to satisfy the greater resource demand, larger aboveground species need to develop a relatively large root system (Westoby and Wright, 2006). Previous studies in karst regions showed that during the early stages of restoration in with infertile soil conditions, plants have not yet developed large root systems, only small shrubs can be supported to survive and thrive (Wen et al., 2015; Zhang et al., 2015), which has also been shown in non-karst studies (A. G. T, 1916; Glenn-Lewin et al., 1993; Jiang et al., 2018). In terms of leaf phenology, compared with the evergreen species, deciduous species require more resources during the rainy season because of their concentrated growth (Hasselquist et al., 2010; Nie et al., 2014b; Wang and Moore, 2014; Delzon, 2015; Salazar-Tortosa et al., 2018). Therefore, P. longipes needs to build a wider range of coarse roots than T. ovoidea to assist the distal roots search for a wider range of resources, especially in shallow soils that have low availability of with low resources and weak weathered bedrock where roots cannot penetrate (Table 2).

Although our results indicated that common plants adapt to soil-limited environments by developing large radial root extent, it still faces some uncertainties due to the lack specific investigation results into fine roots on an individual level. Firstly, in our study, almost all the root on a community level was found in the top $30 \mathrm{~cm}$ of the shallow soil layer (Supplementary Figure S2), however, there might be a small amount of the fine roots distributed in relatively deep layers. Which might lead us to underestimate the ability of plant to absorb deep storage water (Nie et al., 2011; Ding et al., 2018). Secondly, the horizontal distribution of the fine roots on an individual level were also difficult to ascertain precisely. Generally, the fine roots might prefer to concentrate in the soil patches with higher water and nutrient contents (Robinson, 1994; Novoplansky, 2019), rather than distribute equably to a homogeneous water and nutrient absorption, which is considered as a foraging adaptation of roots (Hutchings and Kroon, 1994). Therefore, our study does not sufficiently demonstrate the resource acquisition and utilization strategy of plants without considering the fine roots and prevents the further understanding of plant adaptation mechanism in soillimited environments.

\section{CONCLUSIONS}

To reveal how plants adapt to environmental stress, especially in soil-limited environments, we selected two common species that grow in a shallow rocky soil habitat and a nearby deep soil habitat, measured their foliar chemical indexes and investigated their root structures. Our results showed that the same species exhibited a similar level of water and nutrient utilization in the two contrasting habitats that had greatly different soil water holding capacity and available nutrient content. They also had a wide lateral root extension and a high root to canopy ratio in the shallow soil layer, rather than deep penetration. Specifically, the wide root horizontal range of the tree in the soil-limited habitat was accompanied by low root tapering rate and bending degree. Moreover, the tree species has a more obvious difference in root dimension between contrasting habitat than the shrub. These results provided an interface to study the role of root structure in adapting to environmental water and nutrient restrictions and are essential for sustainable silviculture and exploring vegetation adaptability. Future studies combined the absorptive distal roots and transportive proximal roots may shed more light on plant adaptation strategy and mechanism in in soillimited environments.

\section{DATA AVAILABILITY STATEMENT}

The raw data supporting the conclusions of this article will be made available by the authors, without undue reservation. 


\section{AUTHOR CONTRIBUTIONS}

$\mathrm{YN}$ and $\mathrm{HC}$ contributed conception and design of the study. XM organized the database and performed the statistical analysis. XM wrote the first draft of the manuscript. All authors contributed to the article and approved the submitted version.

\section{FUNDING}

This research was funded by the National Natural Science Foundation of China (41930866 and 31971438), the Guangxi Natural Science Foundation (2018GXNSFGA281003), International Partnership Program of Chinese Academy of Sciences

\section{REFERENCES}

A. G, T (1916). The Development of Vegetation. J. Ecol. 4 (3/4), 198-204. doi: $10.2307 / 2255632$

Aerts, R., and Chapin, F. S. (1999). The Mineral Nutrition of Wild Plants Revisited: A Re-evaluation of Processes and Patterns. Adv. Ecol. Res. 30, 167. doi: 10.1016/s0065-2504(08)60016-1

Baluška, F., Mancuso, S., Volkmann, D., and Barlow, P. (2009). The 'rootbrain'hypothesis of Charles and Francis Darwin: revival after more than 125 years. Plant Signaling Behav. 4 (12), 1121-1127. doi: 10.4161/psb.4.12.10574

Bastida, J. M., Rey, P. J., and Alcántara, J. M. (2013). Plant performance and morphofunctional differentiation in response to edaphic variation in Iberian columbines: cues for range distribution? J. Plant Ecol. 7 (4), 403-412. doi: 10.1093/jpe/rtt046

Brant, A. N., and Chen, H. Y. H. (2015). Patterns and Mechanisms of Nutrient Resorption in Plants. Crit. Rev. Plant Sci. 34 (5), 471-486. doi: 10.1080/ 07352689.2015.1078611

Cao, J., Yuan, D., Zhang, C., and Jiang, Z. (2005). Karst ecosystem constrained by geological conditions in southwest China. Earth Environ. 32 (1), 1-8. doi: 10.3969/j.issn.1672-9250.2004.01.001

Cao, K., Fu, P., Chen, Y., Jiang, Y., and Zhu, S. (2014). Implications of the Ecophysiological Adaptation of Plants on Tropical Karst Habitats for the Ecological Restoration of Desertified Rocky Lands in Southern China. Sci. Sin. Vitae 44 (3), 238-247. doi: 10.1360/052013-234

Chapin, I. F. S., Schulze, E. D., and Mooney, H. A. (1990). The Ecology and Economics of Storage in Plants. Annu. Rev. Ecol. Syst. 21, 423-447. doi: 10.1146/annurev.ecolsys.21.1.423

Chen, H., Liu, J., Wang, K., and Zhang, W. (2011). Spatial distribution of rock fragments on steep hillslopes in karst region of northwest Guangxi, China. Catena 84 (1-2), 21-28. doi: 10.1016/j.catena.2010.08.012

Dammeyer, C., Heather, Schwinning, S., Schwartz, B. F., and Moore, G. (2016). Effects of juniper removal and rainfall variation on tree transpiration in a semiarid karst: evidence of complex water storage dynamics. Hydrol. Processes 30, 4568-4581. doi: 10.1002/hyp.10938

Dawson, T. E., Mambelli, S., Plamboeck, A. H., Templer, P. H., and Tu, K. P. (2002). Stable Isotopes in Plant Ecology. Annu. Rev. Ecol. Syst. 33 (1), 507-559. doi: 10.1146/annurev.ecolsys.33.020602.095451

Dawson, T. E., Hahm, W. J., and Crutchfield-Peters, K. (2020). Digging deeper: what the critical zone perspective adds to the study of plant ecophysiology. New Phytol. 226 (3), 666-671. doi: 10.1111/nph.16410

Delzon, S. (2015). New insight into leaf drought tolerance. Funct. Ecol. 29 (10), 1247-1249. doi: 10.1111/1365-2435.12500

Ding, Y., Nie, Y., Schwinning, S., Chen, H., Yang, J., Zhang, W., et al. (2018). A novel approach for estimating groundwater use by plants in rock-dominated habitats. J. Hydrol. 565, 760-769. doi: 10.1016/j.jhydrol.2018.08.033

Du, H., Hu, F., Zeng, F., Wang, K., Peng, W., Zhang, H., et al. (2017). Spatial distribution of tree species in evergreen-deciduous broadleaf karst forests in southwest China. Sci. Rep. 7 (1), 15664. doi: 10.1038/s41598-017-15789-5 (132852kysb20170029), and the Youth Innovation Promotion Association (2018397) of the Chinese Academy of Sciences.

\section{ACKNOWLEDGMENTS}

We thank Magdeline Laba for checking the English of this paper.

\section{SUPPLEMENTARY MATERIAL}

The Supplementary Material for this article can be found online at: https://www.frontiersin.org/articles/10.3389/fpls.2020.01260/ full\#supplementary-material

Du, H., Liu, L., Su, L., Zeng, F., Wang, K., Peng, W., et al. (2019). Seasonal changes and vertical distribution of fine root biomass during vegetation restoration in a karst area, southwest China. Front. Plant Sci. 9, 2001. doi: 10.3389/ fpls.2018.02001

Elser, J., Sterner, R. W., Gorokhova, E. A., Fagan, W., Markow, T., Cotner, J. B., et al. (2000). Biological stoichiometry from genes to ecosystems. Ecol. Lett. 3 (6), 540-550. doi: 10.1046/j.1461-0248.2000.00185.x

Ennos, A. R. (1993). The Scaling of Root Anchorage. J. Theor. Biol. 161 (1), 61-75. doi: 10.1006/jtbi.1993.1040

Estrada-Medina, H., Santiago, L. S., Graham, R. C., Allen, M. F., and JiménezOsornio, J. J. (2013). Source water, phenology and growth of two tropical dry forest tree species growing on shallow karst soils. Trees 27 (5), 1297-1307. doi: 10.1007/s00468-013-0878-9

Ford, D., and Williams, P. (2013). "Karst Landform Development in Humid Regions [M]//," in Karst Hydrogeology and Geomorphology (Chichester, UK: John Wiley \& Sons Ltd).

Fu, Z., Chen, H., Xu, Q., Jia, J., Wang, S., and Wang, K. (2016). Role of epikarst in near-surface hydrological processes in a soil mantled subtropical dolomite karst slope: implications of field rainfall simulation experiments. Hydrol. Processes 30 (5), 795-811. doi: 10.1002/hyp.10650

Fu, T. G. (2017). Water storage capacity and its influencing factors in a typical small karst catchment (Beijing, China: PhD., Chinese Academy of Sciences).

Glenn-Lewin, D. C., Peet, R. K., and Veblen, T. T. (1993). Plant Succession: Theory and Prediction. J. Ecol. 81 (4), 830. doi: 10.2307/2261684

Graham, R. C., Anderson, M. A., Sternberg, P. D., Tice, K. R., and Schoeneberger, P. J. (1997). Morphology, Porosity, and Hydraulic Conductivity of Weathered Granitic Bedrock and Overlying Soils. Soil Sci. Soc. America J. 61 (2), 516. doi: 10.2136/sssaj1997.03615995006100020021x

Graham, R., Rossi, A., and Hubbert, R. (2010). Rock to regolith conversion: Producing hospitable substrates for terrestrial ecosystems. GSA Today 20 (2), 4-9. doi: 10.1130/gsat57a.1

Gu, D., Zhang, Z., Mallik, A., Zhou, A., Mo, L., He, C., et al. (2015). Seasonal water use strategy of Cyclobalanopsis glauca in a karst area of southern China. Environ. Earth Sci. 74 (2), 1007-1014. doi: 10.1007/s12665-014-3817-1

Güsewell, S. (2004). N : P ratios in terrestrial plants: variation and functional significance. New Phytol. 164 (2), 243-266. doi: 10.1111/j.14698137.2004.01192.x

Han, W., Fang, J., Guo, D., and Zhang, Y. (2005). Leaf nitrogen and phosphorus stoichiometry across 753 terrestrial plant species in China. New Phytol. 168 (2), 377-385. doi: 10.1111/j.1469-8137.2005.01530.x

Hand, R., Grossmann, A., and Lauterbach, D. (2017). Endemics and their common congener plant species on an East Mediterranean island: a comparative functional trait approach. Plant Ecol. 218 (2), 139-150. doi: 10.1007/s11258-016-0673-y

Hasselquist, N. J., Allen, M. F., and Santiago, L. S. (2010). Water relations of evergreen and drought-deciduous trees along a seasonally dry tropical forest chronosequence. Oecologia 164 (4), 881-890. doi: 10.1007/s00442-010-1725-y 
Heilman, J., McInnes, K., Kjelgaard, J., Owens, M. K., and Schwinning, S. (2009). Energy balance and water use in a subtropical karst woodland on the Edwards Plateau, Texas. J. Hydrol. 373 (3-4), 426-435. doi: 10.1016/j.jhydrol.2009.05.007

Henry, H. A., Cleland, E. E., Field, C. B., and Vitousek, P. M. (2005). Interactive effects of elevated $\mathrm{CO} 2, \mathrm{~N}$ deposition and climate change on plant litter quality in a California annual grassland. Oecologia 142 (3), 465-473. doi: 10.1007/ s00442-004-1713-1

Hubbert, K. R., Beyers, J. L., and Graham, R. C. (2001). Roles of weathered bedrock and soil in seasonal water relations of Pinus Jeffreyi and Arctostaphylos patula. Can. J. For. Res. 31 (11), 1947-1957. doi: 10.1139/cjfr-31-11-1947

Hutchings, M. J., and Kroon, H. D. (1994). Foraging in Plants: the Role of Morphological Plasticity in Resource Acquisition. Adv. Ecol. Res. 25, 159-238. doi: 10.1016/S0065-2504(08)60215-9

Isaac, M. E., Anglaaere, L. C. N., Borden, K., and Adu-Bredu, S. (2014). Intraspecific root plasticity in agroforestry systems across edaphic conditions. Agric. Ecosyst. Environ. 185, 16-23. doi: 10.1016/j.agee.2013.12.004

Jackson, R., Moore, L., Hoffmann, W., Pockman, W., and Linder, C. (1999). Ecosystem rooting depth determined with caves and DNA. Proc. Natl. Acad. Sci. 96 (20), 11387-11392. doi: 10.2307/49046

Jiang, X., Huang, J. G., Cheng, J., Dawson, A., Stadt, K. J., Comeau, P. G., et al. (2018). Interspecific variation in growth responses to tree size, competition and climate of western Canadian boreal mixed forests. Sci. Total Environ. 631-632, 1070-1078. doi: 10.1016/j.scitotenv.2018.03.099

Koerselman, W., and Meuleman, A. F. (1996). The vegetation N: P ratio: a new tool to detect the nature of nutrient limitation. J. Appl. Ecol. 33 (6), 1441-1450. doi: $10.2307 / 2404783$

Kong, D., Wang, J., Zeng, H., Liu, M., Miao, Y., Wu, H., et al. (2016). The nutrient absorption-transportation hypothesis: optimizing structural traits in absorptive roots. New Phytol. 213, 1569-1572. doi: 10.1111/nph.14344

Kukowski, K. R., Schwinning, S., and Schwartz, B. F. (2013). Hydraulic responses to extreme drought conditions in three co-dominant tree species in shallow soil over bedrock. Oecologia 171 (4), 819-830. doi: 10.1007/s00442-0122466-x

Ledo, A., Paul, K. I., Burslem, D. F., Ewel, J. J., Barton, C., Battaglia, M., et al. (2018). Tree size and climatic water deficit control root to shoot ratio in individual trees globally. New Phytol. 217 (1), 8-11. doi: 10.1111/nph.14863

Lezberg, A. L., Antos, J. A., and Halpern, C. B. (1999). Belowground traits of herbaceous species in young coniferous forests of the Olympic Peninsula, Washington. Can. J. Bot. 77 (7), 936-943. doi: 10.1139/cjb-77-7-936

Li, H., Liu, B., McCormack, M. L., Ma, Z., and Guo, D. (2017). Diverse belowground resource strategies underlie plant species coexistence and spatial distribution in three grasslands along a precipitation gradient. New Phytol. 216 (4), 1140-1150. doi: 10.1111/NPH.14710

Maeght, J. L., Rewald, B., and Pierret, A. (2013). How to study deep roots-and why it matters. Front. Plant Sci. 4, 299. doi: 10.3389/fpls.2013.00299

Martre, P., North, G. B., Bobich, E. G., and Nobel, P. S. (2002). Root Deployment and Shoot Growth for Two Desert Species in Response to Soil Rockiness. Am. J. Bot. 89 (12), 1933-1939. doi: 10.2307/4122748

Matyssek, R., Koricheva, J., Schnyder, H., Ernst, D., Munch, J., Oßwald, W., et al. (2012). "The balance between resource sequestration and retention: a challenge in plant science," in Growth and defence in plants (Berlin: Springer), 3-24.

McCormack, M. L., Dickie, I. A., Eissenstat, D. M., Fahey, T. J., Fernandez, C. W., Guo, D., et al. (2015). Redefining fine roots improves understanding of belowground contributions to terrestrial biosphere processes. New Phytol. 207 (3), 505-518. doi: 10.1111/nph.13363

Milly, P. (1994). Climate, soil water storage, and the average annual water balance. Water Resour. Res. 30 (7), 2143-2156. doi: 10.1029/94WR00586

Mulia, R., Dupraz, C., and van Noordwijk, M. (2010). Reconciling root plasticity and architectural ground rules in tree root growth models with voxel automata. Plant Soil 337 (1-2), 77-92. doi: 10.1007/s11104-010-0502-3

Ni, J., Luo, D. H., Xia, J., Zhang, Z. H., and Hu, G. (2015). Vegetation in karst terrain of southwestern China allocates more biomass to roots. Solid Earth 6 (3), 799-810. doi: 10.5194/se-6-799-2015

Nie, Y.-p., Chen, H.-S., Wang, K.-L., Tan, W., Deng, P.-Y., and Yang, J. (2011). Seasonal water use patterns of woody species growing on the continuous dolostone outcrops and nearby thin soils in subtropical China. Plant Soil 341 (1-2), 399-412. doi: 10.1007/s11104-010-0653-2
Nie, Y.-p., Chen, H.-S., Wang, K.-L., and Yang, J. (2012). Water source utilization by woody plants growing on dolomite outcrops and nearby soils during dry seasons in karst region of Southwest China. J. Hydrol. 420 (4), 264-274. doi: 10.1016/j.jhydrol.2011.12.011

Nie, Y.-P., Chen, H.-S., Wang, K.-L., and Ding, Y.-L. (2014a). Rooting characteristics of two widely distributed woody plant species growing in different karst habitats of southwest China. Plant Ecol. 215 (10), 1099-1109. doi: 10.1007/s11258-014-0369-0

Nie, Y.-P., Chen, H.-S., Wang, K.-L., and Ding, Y.-L. (2014b). Seasonal variations in leaf $\delta 13 \mathrm{C}$ values: implications for different water-use strategies among species growing on continuous dolomite outcrops in subtropical China. Acta Physiol. Plant. 36 (10), 2571-2579. doi: 10.1007/s11738-014-1628-3

Nie, Y. P., Chen, H. S., Wang, K. L., and Schwinning, S. (2017). Challenges and probable solutions for using stable isotope techniques to identify plant water sources in karst regions: A review. Chin. J. Appl. Ecol. 28 (7), 2361-2368. doi: 10.13287/J.1001-9332.201707.017

Novoplansky, A. (2019). What plant roots know. Semin. Cell Dev. Biol. 92, 126133. doi: 10.1016/J.SEMCDB.2019.03.009

O’Donnell, F. C., Caylor, K. K., Bhattachan, A., Dintwe, K., D’Odorico, P., and Okin, G. S. (2015). A quantitative description of the interspecies diversity of belowground structure in savanna woody plants. Ecosphere 6 (9), art154. doi: 10.1890/es14-00310.1

Peek, M. S., Leffler, A. J., Ivans, C. Y., Ryel, R. J., and Caldwell, M. M. (2005). Fine root distribution and persistence under field conditions of three co-occurring Great Basin species of different life form. New Phytol. 165 (1), 171-180. doi: $10.1111 / j .1469-8137.2004 .01186 . x$

Phillips, W. S. (1963). Depth of Roots in Soil. Ecology 44 (2), 424. doi: 10.2307/ 1932198

Poorter, H., Niklas, K. J., Reich, P. B., Oleksyn, J., Poot, P., and Mommer, L. (2012). Biomass allocation to leaves, stems and roots: meta-analyses of interspecific variation and environmental control. New Phytol. 193 (1), 30-50. doi: 10.1111/ j.1469-8137.2011.03952.x

Poot, P., and Lambers, H. (2008). Shallow-soil endemics: adaptive advantages and constraints of a specialized root-system morphology. New Phytol. 178 (2), 371381. doi: $10.1111 / j .1469-8137.2007 .02370 . x$

Pregitzer, K. S., DeForest, J. L., Burton, A. J., Allen, M. F., Ruess, R. W., and Hendrick, R. L. (2002). Fine Root Architecture of Nine North American Trees. Ecol. Monogr. 72 (2), 293-309. doi: 10.2307/3100029

Prieto, I., Querejeta, J. I., Segrestin, J., Volaire, F., Roumet, C., and Oliveira, R. (2018). Leaf carbon and oxygen isotopes are coordinated with the leaf economics spectrum in Mediterranean rangeland species. Funct. Ecol. 32 (3), 612-625. doi: 10.1111/1365-2435.13025

Querejeta, J. I., Estrada-Medina, H., Allen, M. F., Jiménez-Osornio, J. J., and Ruenes, R. (2006). Utilization of bedrock water by Brosimum alicastrum trees growing on shallow soil atop limestone in a dry tropical climate. Plant Soil 287 (1-2), 187-197. doi: 10.1007/s11104-006-9065-8

Querejeta, J. I., Estrada-Medina, H., Allen, M. F., and Jimenez-Osornio, J. J. (2007). Water source partitioning among trees growing on shallow karst soils in a seasonally dry tropical climate. Oecologia 152 (1), 26-36. doi: 10.1007/s00442006-0629-3

Querejeta, J. I., Prieto, I., Torres, P., Campoy, M., Alguacil, M. M., and Roldán, A. (2018). Water-spender strategy is linked to higher leaf nutrient concentrations across plant species colonizing a dry and nutrient-poor epiphytic habitat. Environ. Exp. Bot. 153, 302-310. doi: 10.1016/j.envexpbot.2018.06.007

Rawls, W. J., Brakensier, D. L., and Saxton, K. E. (1982). Estimation of Soil Water Properties. Trans. Am. Soc. Agricural. Eng. 25, 1316-1320. doi: 10.13031/ 2013.33720

Reynolds, J., and Thornley, J. (1982). A shoot: root partitioning model. Ann. Bot. 49 (5), 585-597. doi: 10.1093/oxfordjournals.aob.a086286

Robinson, D. (1994). The responses of plants to non-uniform supplies of nutrients. New Phytol. 127 (4), 635-674. doi: 10.1111/J.1469-8137.1994.TB02969.X

Rong, L., Wang, S., Yu, G., Deng, X., and Ran, J. (2012). Stable Isotope Analysis of Water Sources of Four Woody Species in the Libo Karst Forest. Sci. Silvae Sinicae 48 (7), 14-22.

Salazar-Tortosa, D., Castro, J., Villar-Salvador, P., Vinegla, B., Matias, L., Michelsen, A., et al. (2018). The "isohydric trap": A proposed feedback between water shortage, stomatal regulation, and nutrient acquisition drives 
differential growth and survival of European pines under climatic dryness. Glob. Chang Biol. 24 (9), 4069-4083. doi: 10.1111/gcb.14311

Schenk, H. J., and Jackson, R. B. (2002). Rooting depths, lateral root spreads and below-ground/above-ground allometries of plants in water-limited ecosystems. J. Ecol. 90 (3), 480-494. doi: 10.1046/j.1365-2745.2002.00682.x

Schenk, H. J., and Jackson, R. B. (2005). Mapping the global distribution of deep roots in relation to climate and soil characteristics. Geoderma 126 (1-2), 129140. doi: 10.1016/j.geoderma.2004.11.018

Schenk, H. J. (2008a). The Shallowest Possible Water Extraction Profile: A Null Model for Global Root Distributions. Vadose Zone J. 7 (3), 1119. doi: 10.2136/ vzj2007.0119

Schenk, H. J. (2008b). Soil depth, plant rooting strategies and species' niches. New Phytol. 178 (2), 223-225. doi: 10.1111/j.1469-8137.2008.02427.x

Schwinning, S. (2010). The ecohydrology of roots in rocks. Ecohydrology 3, 238245. doi: 10.1002/eco.134

Schwinning, S. (2013). Do we need new rhizosphere models for rock-dominated landscapes? Plant Soil 362 (1-2), 25-31. doi: 10.1007/s11104-012-1482-2

Semchenko, M., Lepik, A., Abakumova, M., and Zobel, K. (2018). Different sets of belowground traits predict the ability of plant species to suppress and tolerate their competitors. Plant Soil 424 (1), 157-169. doi: 10.1007/s11104-017-3282-1

Shan, L. S., Zhang, X. M., Hua, Y. H., Jiang, W., Yan, H. L., Ting-Ting, et al. (2007). Response of Root Distribution of Haloyxlon Ammodendron Seedlings to Irrigation Amounts in the Taklimakan Desert, China. J. Plant Ecol. 31 (5), 769-776. doi: 10.1007/s11461-009-0002-x

Steele, S. J., Gower, S. T., Vogel, J. G., and Norman, J. M. (1997). Root mass, net primary production and turnover in aspen, jack pine and black spruce forests in Saskatchewan and Manitoba, Canada. Tree Physiol. 17, 577-587. doi: 10.1093/TREEPHYS/17.8-9.577

Sternberg, P., Anderson, M., Graham, R., Beyers, J., and Tice, K. (1996). Root distribution and seasonal water status in weathered granitic bedrock under chaparral. Geoderma 72, 89-98. doi: 10.1016/0016-7061(96)00019-5

Stone, E. L., and Kalisz, P. J. (1991). On the maximum extent of tree roots. For. Ecol. Manage. 46 (1-2), 59-102. doi: 10.1016/0378-1127(91)90245-Q

Valverde-Barrantes, O. J., Freschet, G. T., Roumet, C., and Blackwood, C. B. (2017). A worldview of root traits: the influence of ancestry, growth form, climate and mycorrhizal association on the functional trait variation of fine-root tissues in seed plants. New Phytol. 215 (4), 1562-1573. doi: 10.1111/nph.14571
Wang, M., and Moore, T. R. (2014). Carbon, Nitrogen, Phosphorus, and Potassium Stoichiometry in an Ombrotrophic Peatland Reflects Plant Functional Type. Ecosystems 17 (4), 673-684. doi: 10.1007/s10021-014-9752-x

Wang, S., Fu, Z., Chen, H., and Xu, Q. (2019). Mechanisms of surface and subsurface runoff generation in subtropical soil-epikarst systems: Implications of rainfall simulation experiments on karst slope. J. Hydrol. 580:124370. doi: 10.1016/j.jhydrol.2019.124370

Wen, L., Song, T., Du, H., Wang, K., and He, T. (2015). The succession characteristics and its driving mechanism of plant community in karst region, Southwest China. Acta Ecol. Sin. 35 (17), 5822-5833. doi: 10.5846/ stxb201310192524

Westoby, M., and Wright, I. J. (2006). Land-plant ecology on the basis of functional traits. Trends Ecol. Evol. 21 (5), 261-268. doi: 10.1016/ j.tree.2006.02.004

Yang, J., Chen, H., Nie, Y., and Wang, K. (2012). Variation of precipitation characteristics and shallow groundwater depth in the typical karst peak-cluster depression areas. J. Soil Water Conserv.(China) 26, 239-243.

Yu, L. (2003). Primary study on the structure of bud popilation for platycarya Longipes. Guizhou Sci. 21 (1-2), 64-68.

Zhang, W., Zhao, J., Pan, F., Li, D., Chen, H., and Wang, K. (2015). Changes in nitrogen and phosphorus limitation during secondary succession in a karst region in southwest China. Plant Soil 391 (1-2), 77-91. doi: 10.1007/s11104015-2406-8

Zwieniecki, M. A., and Newton, M. (1995). Root distribution of 12-year-old forests at rocky sites in southwestern Oregon: effects of rock physical properties. Can. J. For. Res. 24 (9), 1791-1796. doi: 10.1139/x94-231

Conflict of Interest: The authors declare that the research was conducted in the absence of any commercial or financial relationships that could be construed as a potential conflict of interest.

Copyright $\odot 2020 \mathrm{Ma}$, Chen and Nie. This is an open-access article distributed under the terms of the Creative Commons Attribution License (CC BY). The use, distribution or reproduction in other forums is permitted, provided the original author $(s)$ and the copyright owner(s) are credited and that the original publication in this journal is cited, in accordance with accepted academic practice. No use, distribution or reproduction is permitted which does not comply with these terms. 